\title{
Aplicação das Ferramentas da Qualidade na Solução de Problemas de Contaminação em uma Fábrica de Chocolate
}

\author{
Application of quality tools to solve contamination problems in a chocolate factory
}

\author{
Priscilla Ferreira Corrêa ${ }^{1}$ \\ Luciana Bazante de Oliveira ${ }^{2}$ \\ ${ }^{1}$ Escola Politécnica de Pernambuco, Universidade de Pernambuco, Recife, Brasil \\ E-mail do autor principal: Priscilla Ferreira Corrêa priscilla.correa.pe@gmail.com
}

\section{Resumo}

Com o crescimento do capitalismo, houve o aumento do consumo e do número de empresas. Devido a isso, os consumidores começaram a ficar cada vez mais exigentes com relação à qualidade dos produtos/serviços, forçando tais empresas a uma busca por melhorias nos seus produtos e processos, visando a satisfação dos mesmos. Nesse contexto, surgiram metodologias que atualmente são bastante difundidas nas empresas, como o Controle da Qualidade Total (TQC). De forma a auxiliar na aplicação do TQC, é utilizado como base o ciclo PDCA, que atua no planejamento, execução e verificação dos processos para resolver problemas ou proporcionar melhoria, usando as ferramentas da qualidade para a execução eficiente do ciclo. Neste trabalho acadêmico, com base nos conceitos de TQC e PDCA, foi aplicada uma pesquisa de campo numa fábrica de chocolate na Região Metropolitana do Recife, bem como usadas algumas das principais ferramentas da qualidade na identificação, análise e solução do problema de chocolate contaminado, o que tornou possível identificar as causas raízes de tal problema. As ferramentas da qualidade, aliadas aos conceitos do TQC, foram essenciais para reconhecimento e solução da contaminação dos produtos, além de serem muito importantes para a melhoria e crescimento contínuo da empresa.

Palavras-Chave: Controle da Qualidade Total; PDCA; Ferramentas da Qualidade; Fábrica de Chocolate.

\begin{abstract}
Through the growth of capitalism, there was an increase in consumption and in the number of companies. Because of that, consumers became more demanding about the quality of products/services, forcing companies to search for improvement in their products and processes, in order to achieve customer's satisfaction. In this context, methodologies that are currently used on companies have emerged, such as Total Quality Control (TQC). Due to assist the application of TQC, the PDCA cycle is used as a premise for planning, execution and verification of processes, to solve problems or provide improvement, using quality tools to achieve an efficient execution of the cycle. In this academic work, based on the concepts of TQC and PDCA, a research was applied on an industry of Recife's Metropolitan Region and some of the main quality tools were applied to identify, analyze and solve the problem of contaminated chocolate, which made possible to observe and solve the roots of the problem. Quality tools, combined with TQC concepts, were essential for product contamination recognition and solution, as well as being very important for the continuous improvement and growth of the company.
\end{abstract}

Key-words: Total Quality Control; PDCA; Quality tools; Chocolate Factory. 


\section{Introdução}

As primeiras preocupações com qualidade surgiram desde cedo, com os artesãos. Contudo, com a consolidação do capitalismo e o aumento da concorrência, passou a crescer a exigência por produtos e serviços melhores. Dessa forma, começaram a surgir pesquisadores que se interessaram por estudar a qualidade dos produtos e serviços. Segundo Filho [1], o conceito de qualidade é dinâmico e sua definição foi evoluindo ao longo dos últimos séculos, surgindo várias formas de se perceber a qualidade do produto ou serviço. É nesse contexto de evolução e estudos sobre a qualidade que surge o Controle da Qualidade Total - Total Quality Control (TQC), possibilitando às empresas a identificação dos problemas ainda durante o processo, diminuindo assim o custo com perdas.

O TQC foi uma das estratégias das empresas, para melhorarem seus produtos e/ou serviços, que faz uso do ciclo PDCA (do inglês: Plan-Do-Check-Act) como base para melhoria contínua dos processos, sendo que ambos fazem uso das ferramentas da qualidade. Algumas das ferramentas mais utilizadas são: o diagrama de Pareto, diagrama de Ishikawa, histograma, lista de verificação, brainstorming e o $5 \mathrm{~W} 2 \mathrm{H}$. Tais ferramentas são utilizadas como apoio para a melhoria contínua dos processos e produtos/serviços de uma empresa.

Um segmento que vem se destacando com o uso das técnicas do TQC e PDCA é o alimentício. Segundo Maluf [2], a qualidade do sistema industrial de alimentos está associada à estrutura e às ferramentas de garantia de qualidade, ambas desenvolvidas e dimensionadas tendo em vista a realidade e a escala de produção de médias e grandes empresas, a partir dos riscos envolvidos na produção e transporte de alimentos em massa.

Uma fábrica de chocolate da Região Metropolitana do Recife teve a iniciativa de aplicar os conceitos do TQC, juntamente com as ferramentas da qualidade, para melhorar a qualidade de seus produtos. Trata-se de uma empresa de pequeno porte que foi fundada em 1998 e, inicialmente, só produzia artigos para chocolate artesanais. Em 2009, começou a efetivamente produzir suas próprias marcas de chocolate e cobertura. Atualmente, a empresa está em elevado crescimento no mercado pernambucano e revendendo seus produtos para vários estados do Nordeste. Possui em Pernambuco 6 lojas e uma loja na Bahia, que tem como carro chefe os produtos fabricados pela fábrica, mas comercializa outros itens.
O presente trabalho aplicará O TQC, sob as premissas do PDCA, em uma fábrica de chocolate para regularizar o processo e solucionar problemas de contaminação que estão afetando a satisfação do cliente. A utilização das ferramentas da qualidade será necessária para que a empresa venha a conhecer as causas dos seus problemas e solucioná-los.

\section{Revisão da Literatura}

\subsection{Evolução da Qualidade}

Do fim da Idade Média até o Século XVIII, antes da Revolução Industrial, as oficinas artesanais produziam as mercadorias que eram consumidas. Os artesãos produziam de forma independente, controlando empiricamente o processo de produção e a qualidade. Eles decidiam qual seria a sua jornada de trabalho e, como não havia a divisão das atividades, os trabalhadores da oficina se dedicavam inteiramente a um produto de cada vez [3].

A partir do século XVIII, com o aumento populacional, cresceu a demanda pelo consumo, o que levou os artesãos a aumentarem a produção, a reorganizar o espaço de trabalho e a iniciar a divisão de tarefas. Com o surgimento da industrialização, houve a necessidade de separação entre a figura do produtor, responsável direto pelo espaço da produção, agora em maior escala e a figura do comerciante, responsável pela distribuição dos produtos manufaturados [4].

Diante da implantação do sistema de fábricas, advindo da Revolução Industrial por volta de 1773, uma nova configuração da produção se impôs com outras tecnologias, trabalhadores assalariados, divisão do trabalho e baixo nível de controle sobre o produto. Todas essas mudanças na valorização do produto/serviço influenciaram na alteração da estrutura econômica mundial [5].

Por volta de 1911, fortaleceu-se a produção em massa. Ao publicar 'Os princípios da administração científica', o engenheiro norte americano Frederick W. Taylor propôs a hierarquização e a intensificação da divisão das etapas do processo produtivo, de modo que cada trabalhador realizasse tarefas muito específicas e repetitivas, também incentivou a entrega de prêmios para quem produzisse mais [3]. O Taylorismo trazia consigo novas formas de pensar e de aplicar a produção, o foco era a melhoria do processo no qual cada operador tinha uma função especifica em cada etapa do processo de fabricação. 
Henry Ford foi um dos pioneiros em implantar o Taylorismo em sua empresa automobilística. Ele inovou o seu processo industrial ao organizar uma linha de montagem na fábrica para aumentar a sua produção e, com essa adaptação, foi possível controlar melhor as fontes de matérias-primas e de energia, a formação de mão de obra e o transporte. Segundo Ferreira [3], as aplicações de Ford ficaram conhecidas como a era da inspeção. Nesse período, o foco estava no produto, não havendo uma busca formal pela qualidade durante o processo de produção, e sim a realização de uma vistoria ao seu término. Foi somente após a Primeira Guerra Mundial que se começou a busca por um melhor controle da produção, por meio do surgimento de novas técnicas de amostragem e procedimentos de controle estatístico nos processos administrativos, havendo a criação do departamento de controle de qualidade [6].

Em meados de 1930, Walter Shewhart e William Deming, atualmente considerados como gurus da qualidade, desenvolveram e divulgaram uma das metodologias mais difundidas e aplicadas atualmente, o ciclo PDCA, que é constituído por questionamentos repetidos dos detalhados processos de uma operação [3].

Walter Shewhart fazia uso de ferramentas estatísticas para examinar quando uma ação corretiva deveria ser aplicada ao processo. Ele conseguiu desenvolver o Controle Estatístico do Processo (CEP), um dos controles praticados na operação, pela criação de técnicas de acompanhamento e avaliação da produção a partir dos princípios da probabilidade e estatística [3]. Após o surgimento do CEP, passou a ser incentivado o treinamento na área de controle da qualidade para que essas novas técnicas fossem incorporadas e, assim, a prática da inspeção fosse reduzida.

Outro importante pesquisador foi Joseph M. Juran, que em 1951 publicou o Quality control handbook (manual do controle da qualidade). Ele considerava que a existência de padrões, tais como: especificações, processos, requisitos, eram importantes para que os envolvidos nos procedimentos soubessem as suas responsabilidades e objetivos, e salientava que para a empresa, o seu foco deveria ser: satisfazer o cliente e prover uma ausência de deficiência [3].

Com o aumento da complexidade dos sistemas de fabricação e montagem, grande atenção passou a ser dada ao controle da variação das características dos produtos, para garantir que eles estariam conforme os padrões pré-estabelecidos. A maioria das operações passou a usar a amostragem para checar a qualidade de seus produtos ou serviços [3]. Juran sugeria, em suas ideias de qualidade, as técnicas do CEP definidas por Shewhart, mostrando que uma filosofia não excluía a outra.

Philip Crosby foi mais um importante estudioso da qualidade dos produtos. Ele definiu qualidade como conformidade com os requisitos, voltada inteiramente para o cliente, enfatizando que a qualidade é gerenciável e pode ser medida. Ele sugeriu que a qualidade fosse medida pelo custo da não qualidade, que definiu como gastos relacionados à não conformidade ou, em outras palavras, os custos de realizar as coisas erradas [7].

Observa-se que a qualidade do produto ou serviço evoluiu bastante ao longo dos séculos. Segundo Filho [1], a evolução da qualidade é composta por quatro estágios denominados de eras da qualidade. Nessa evolução, cada era da qualidade apresentou a qualidade sob um ângulo diferente, provocando mudanças nas práticas, nas prioridades e nas responsabilidades das empresas. Por se tratar de uma evolução, cada estágio complementa o estágio seguinte, sendo assim identificados:

- a inspeção da qualidade;

- o controle da qualidade estatisticamente;

- a garantia da qualidade: estratégia de gestão em que se procura otimizar a produção e reduzir os custos (financeiros, humanos etc.);

- a gestão da qualidade total.

Segundo Falconi [8], a qualidade total são todas aquelas dimensões que afetam a satisfação das necessidades das pessoas e, por conseguinte, a sobrevivência da empresa. Essas dimensões, ou pilares da qualidade, são premissas básicas para a sobrevivência da empresa e satisfação do cliente, conforme pode ser visualizado na Figura 1.

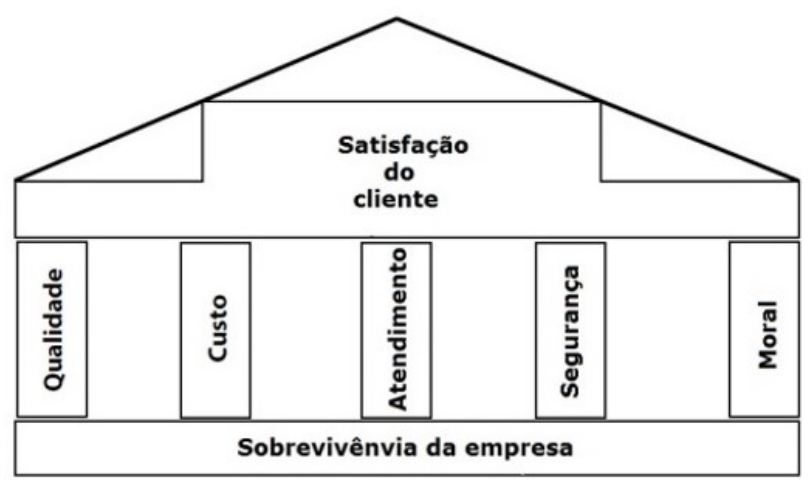

Figura 1: Pilares da qualidade. [adaptado]

http://dx.doi.org/10.25286/repa.v2i2.557 
De acordo com Falconi [8], os pilares ou dimensões da qualidade podem ser classificados conforme a seguir:

- Qualidade: está diretamente ligada à satisfação do cliente interno e externo, sendo medida por meio das características da qualidade dos produtos ou serviços;

- Custo: não é visto somente como custo final do produto ou serviço, mas inclui também os custos intermediários;

- Atendimento: são medidas as condições de entrega dos produtos ou serviços finais $e$ intermediários de uma empresa;

- Moral: mede o nível médio de satisfação de um grupo de pessoas; e

- Segurança: avalia a segurança dos empregados e a segurança dos usuários do produto.

Os cincos pilares da qualidade ou o QCAMS são essenciais para que uma empresa tenha uma boa estrutura com relação a sua capacidade nos produtos ou serviços. A satisfação do cliente é o que faz uma empresa sobreviver, sendo assim, se algum dos pilares estiver mal estruturado, o cliente pode perceber o reflexo na qualidade final do produto ou serviço. O TQC se torna então um caminho para que os 5 pilares da qualidade sejam atendidos, de forma que as expectativas dos clientes também o sejam e a empresa atinja o lucro esperado.

\subsection{Controle da Qualidade Total - TQC}

Uma forma de melhorar os níveis de qualidade dos produtos, dos serviços e dos processos é o controle da qualidade total ou TQC, que é um sistema administrativo aperfeiçoado no Japão, a partir de ideias americanas introduzidas logo após a Segunda Guerra Mundial, baseado na participação de todos os setores da empresa e todos os empregados no estudo e na condução do controle da qualidade [8].

Ele tem como base elementos de várias fontes: emprega o método cartesiano, aproveita muito do trabalho de Taylor, utiliza o CEP, adota os conceitos sobre comportamento humano e aproveita todo o conhecimento ocidental sobre qualidade, principalmente o trabalho de Juran. O TQC é a junção de vários métodos voltados para a melhoria e aperfeiçoamento da empresa [8].

O controle da qualidade tem como objetivo principal buscar as causas dos problemas e atuar sob os mesmos para controlá-los e satisfazer da melhor forma os clientes desde os internos até os externos
[8].

O TQC é regido pelos seguintes princípios:

- Produzir e fornecer produtos e/ou serviços que atendam concretamente às necessidades do cliente;

- Garantir a sobrevivência da empresa por meio do lucro contínuo adquirido pelo domínio da qualidade;

- Identificar o problema mais crítico e solucionálo pela mais alta prioridade;

- Falar, raciocinar e decidir com dados e com base em fatos;

- Gerenciar a empresa ao longo do processo, e não por resultados;

- Reduzir metodicamente as dispersões por meio do isolamento de suas causas fundamentais;

- Não permitir a venda de produtos defeituosos;

- Procurar prevenir a origem de problemas cada vez mais a montante;

- Nunca permitir que o mesmo problema se repita pela mesma causa;

- Respeitar os empregados como seres humanos independentes;

- Definir e garantir a execução da visão e estratégia da alta direção da empresa.

O TQC usa como base para melhoria contínua dos processos o ciclo PDCA, difundido por Deming. Este ciclo realiza um planejamento de identificação, execução, verificação e padronização dos processos.

\subsection{O Ciclo PDCA}

Desenvolvido por Walter Shewhart, por volta de 1930, difundido posteriormente por William Deming, o ciclo PDCA (do inglês: Plan-Do-Check-Act) foi estruturado a partir de quatro etapas, sendo constituído por questionamentos repetidos dos detalhados processos de uma operação [3].

A primeira das etapas é o P (Plan - Planejar) - onde é necessário identificar os problemas ou metas, analisar as características do problema (ou dos entraves para atingir a melhoria), para traçar as estratégias e ações para resolver o problema ou atingir a meta; a segunda etapa é o $D$ ( $D o$ - Fazer) é nesse ponto que a empresa irá executar aquilo que foi planejado na etapa anterior; a terceira etapa é o C (Check - Avaliar) - verificar se os resultados esperados foram atingidos; e a quarta etapa é o A (Action - Ação corretiva) - esta diretamente ligada à etapa $C$, se na verificação foi percebido que algo ocorreu diferente do planejado, devem ser providenciadas as correções necessárias, revisando as 
atividades, para atingir os resultados esperados.

O ciclo PDCA é um método de melhoria continua que apresenta um formato circular, para transmitir a ideia de que a melhoria deve ser constante, o que é denominado girar o PDCA. A Figura 2 apresenta alguns detalhes sobre as fases do ciclo PDCA.

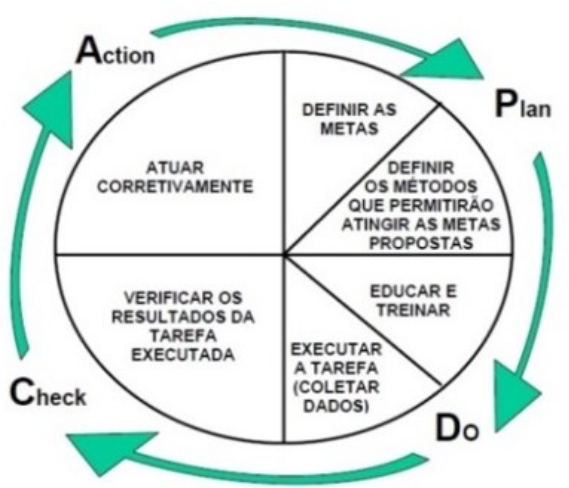

Figura 2: Ciclo PDCA. [12]

Como visto na Figura 2, as etapas do PDCA tem atividades bem definidas e propiciam a melhoria dos produtos e processos. Somente através do uso eficiente do ciclo PDCA, é possível atingir a chamada melhoria contínua dos processos da empresa. No entanto, as etapas devem ser consistentes, através de metas desafiadoras e com uma constante análise da situação indesejada.

Segundo Silva e Barbosa [9] as ferramentas da qualidade são utilizadas no ciclo PCDA para complementar a avaliação e melhoramento do processo. O uso destas tecnologias associadas ao processo da gestão da qualidade possibilita o aumento da produtividade e, por conseguinte, influencia a sua própria competitividade. Essas tecnologias podem representar um fator estratégico e competitivo para o ambiente operacional, com relação a grande variedade de opções de arranjos do fluxo de trabalho que repercutirá no pronto atendimento ao cliente.

\subsection{O Ciclo PDCA}

Para gerenciar os processos e, sobretudo, tomar decisões com maior precisão, se faz necessário trabalhar com base em fatos e dados, ou seja, informações geradas no processo buscando e interpretando corretamente as informações disponíveis como forma de eliminar o empirismo [10].
As ferramentas da qualidade aplicadas neste trabalho são algumas das mais utilizadas mundialmente: o gráfico de Pareto, diagrama de Ishikawa, histograma, lista de verificação, brainstorming, $5 \mathrm{~W} 2 \mathrm{H}$. Tais ferramentas passam a ser de grande utilidade no momento em que as pessoas que compõem a organização começam a dominar e praticar o ciclo PDCA, com a necessidade de trabalhar e dominar as técnicas de tratamento das informações, denominadas ferramentas da qualidade dentro do sistema de gestão pela qualidade e produtividade [10].

Quando aplicadas na análise de problemas, um dos primeiros passos é a identificação correta da falha. De acordo com Falconi [8], a identificação inicial do problema decorre de um resultado indesejável.

Antes de iniciar a utilização das ferramentas da qualidade que apoiam no monitoramento do processo e análise das causas dos problemas, normalmente é utilizada a ferramenta brainstorming. Conhecida também como tempestades de ideias, ela envolve pessoas que farão conhecer suas ideias tanto sobre as causas de algum problema quanto sobre soluções relacionadas a ele.

\subsubsection{Gráfico de Pareto}

O gráfico de Pareto permite priorizar quantitativamente os itens mais importantes. Segundo o principio do economista italiano Vilfred Pareto, muitos itens são triviais e poucos são vitais. A análise de Pareto divide um problema grande em problemas pequenos, prioriza os projetos mais importantes e viabiliza o estabelecimento de metas [8].

O princípio de Pareto é conhecido pela proporção $80 / 20$. É comum que $80 \%$ dos problemas resultem de cerca de apenas $20 \%$ das causas potenciais. Dito de outra forma, $20 \%$ dos nossos problemas causam $80 \%$ das dores de cabeça [11]. A Figura 3 mostra um exemplo de como é montado o diagrama de Pareto. 


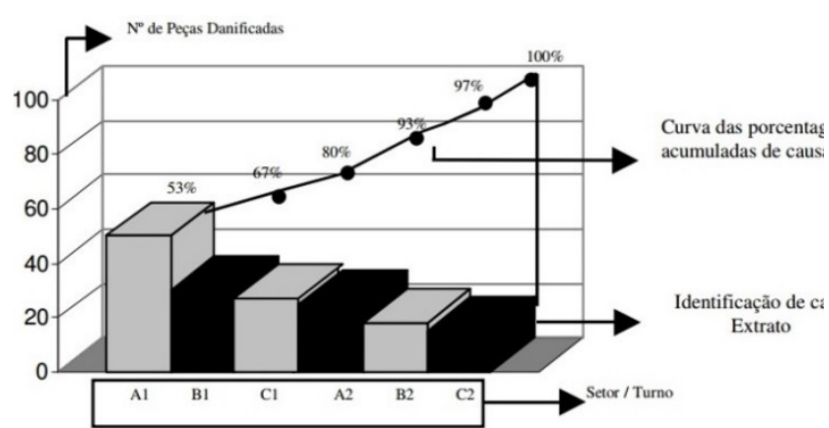

Figura 3: Gráfico de Pareto. [10]

\subsubsection{Diagrama de Causa e Efeito}

O diagrama de causa e efeito (ou espinha de peixe) é uma técnica largamente utilizada, que mostra a relação entre um efeito (problema) e as possíveis causas que podem estar contribuindo para que ele ocorra. Com a aparência de uma espinha de peixe, essa ferramenta foi aplicada, pela primeira vez em 1953 no Japão por Kaoru Ishikawa [12].

Ela pode ser utilizada para organizar as ideias obtidas no brainstorming, facilitando a verificação e identificação das possíveis causas de um problema e, também, identificação de suas soluções. O diagrama de causa e efeito é também conhecido como $6 \mathrm{M}$, pois ele é dividido em seis causas possíveis: máquina, mão de obra, material, método, meio ambiente e medida. Para organizar este diagrama primeiro, é identificado o efeito do problema a ser estudado, que é registrado na desenho que representa a cabeça do peixe e, em seguida, são registradas, nas espinhas, as causas que podem provocar o problema como mostra a Figura 4.

Causa

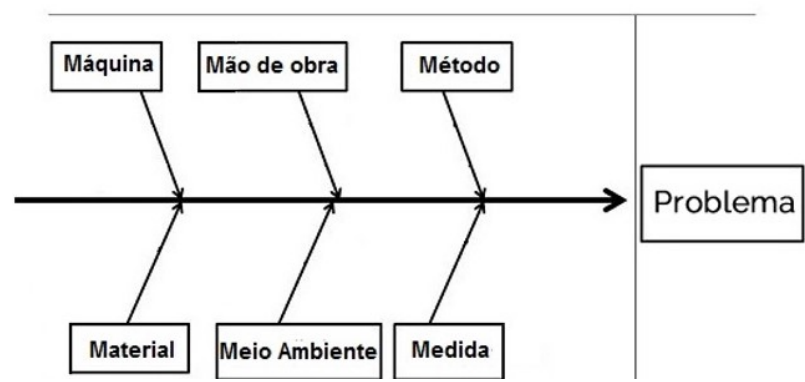

Figura 4: Diagrama de Ishikawa. [adaptado]

O diagrama de Ishikawa é utilizado para buscar a origem das não conformidades e suas interrelações em um processo. Ele permite estruturar hierarquicamente as causas de um determinado problema ou oportunidade de melhoria, podendo ser utilizado para estruturar qualquer sistema que resulte em uma resposta (uni ou multivariada) de forma gráfica e sintética [1].

\subsubsection{Ferramentas para Coleta e Apresentação de Dados}

A coleta de dados é a utilização de técnicas através das quais serão coletadas informações para identificar o problema ou justificar a sua solução, sendo as listas de verificações e fichas de análises as técnicas mais comuns para coletar os dados.

As listas de verificações são listas com itens préestabelecidos que serão marcados a partir do momento em que forem realizadas ou avaliadas. Uma lista de verificação de frequência é usada para determinar quantas vezes ocorreu um evento ao longo de um período de tempo determinado [12].

Embora a finalidade da lista de verificação seja o acompanhamento de dados e não a sua análise, ela normalmente indica qual é o problema e permite observar, entre outros, os seguintes aspectos: número de vezes em que alguma coisa acontece; tempo necessário para que alguma coisa seja feita; custo de uma determinada operação ao longo de certo período de tempo; impacto de uma ação ao longo de um dado período de tempo. A Figura 5 mostra um exemplo de como a lista de verificação [12].

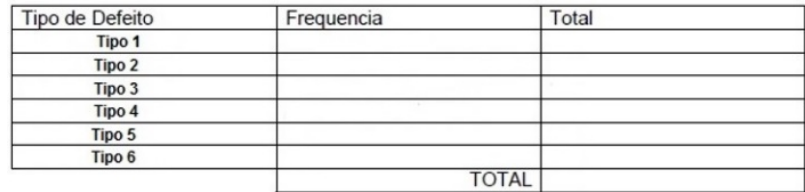

Figura 5: Lista de verificação de frequência. [adaptado]

Por sua vez, os gráficos são instrumentos utilizados para visualizar dados numéricos, facilitando o entendimento do significado dos números. Utilizado para analisar as tendências, as sequências e as comparações entre duas variáveis, tornando mais evidente e compreensível a sua apresentação [12].

Os gráficos no estilo histogramas são usados com frequência para apresentar os resultados das coletas de dados. Os histogramas são gráficos de barras, os quais representam o comportamento de uma coleta 
de dados, suas principais funções são demonstrar como está a variação de uma determinada atividade, o comportamento de um processo produtivo, além de que permite análise de resultados contra padrões de especificação e auxilia na tomada de decisões gerenciais [12].

Os histogramas e as listas de verificações reúnem informações essenciais para o controle de qualidade do produto. Tais dados irão gerar informações cruciais sobre conformidades ou não conformidades dos produtos ou serviços e irão traçar caminhos para planos de ações futuros.

\subsubsection{W2H (Plano de Ação)}

Para auxiliar no planejamento das ações a serem desenvolvidas, é possível utilizar uma ferramenta chamada $5 \mathrm{~W} 2 \mathrm{H}$. Essa ferramenta é utilizada para planejar a implementação de uma solução, sendo elaborada em resposta às questões a seguir [12]:

- What (O que): Que ação vai ser desenvolvida?

- When (Quando): Quando a ação será realizada?

- Why (Por que): Por que foi definida esta solução (resultado esperado)?

- Where (Onde): Onde a ação será desenvolvida (abrangência)?

- How (Como): Como a ação vai ser implementada (passos da ação)?

- Who (Quem): Quem será o responsável pela sua implantação?

- How much (Quanto): Quanto será gasto?

Utilizando esse quadro de perguntas, é possível visualizar a solução adequada de um problema, com possibilidades de acompanhamento da execução de uma ação com mais facilidade [12]. A Figura 6 apresenta uma parte da aplicação do $5 \mathrm{~W} 2 \mathrm{H}$ para o problema de contaminação das trufas, a ser apresentado em sua íntegra nos resultados do presente trabalho.

\begin{tabular}{|c|c|c|c|c|c|c|c|}
\hline \multicolumn{2}{|c|}{$\begin{array}{l}\text { Elaborado por: } \\
\text { Priscilla Corrêa }\end{array}$} & \multicolumn{3}{|c|}{ PLANO DE AÇÃO: TRUFAS CONTAMINADAS } & \multicolumn{2}{|c|}{$\begin{array}{l}\text { SETOR: } \\
\text { Produçâo }\end{array}$} & DATA : \\
\hline $\begin{array}{c}\text { CAUSA } \\
\text { RAIZ }\end{array}$ & OQUE FAZER? & $\begin{array}{c}\text { POR QUE FAZER } \\
?\end{array}$ & QUEM? & $\begin{array}{c}\text { QUANDO } \\
?\end{array}$ & $\begin{array}{c}\text { COMO FAZER } \\
?\end{array}$ & $\begin{array}{c}\text { ONDE } \\
\text { FAZER? }\end{array}$ & $\begin{array}{c}\text { QUANTO } \\
?\end{array}$ \\
\hline \multirow{2}{*}{$\begin{array}{l}\text { CONTROLE } \\
\text { DE PRAGAS } \\
\text { INEFICIENTE }\end{array}$} & $\begin{array}{l}\text {-REALIZAR A } \\
\text { TROCA DA } \\
\text { EMPRESA }\end{array}$ & \begin{tabular}{|c} 
NÄO DEVE \\
APRESENTAR \\
TRAÇAS DO \\
CACAU NA ÄREA \\
DA PRODUÇÄO
\end{tabular} & $\begin{array}{c}\text { EMPRESA } \\
\text { ESPECIALIZADA }\end{array}$ & IIMEDIATO & \begin{tabular}{|c|} 
REALLZAR \\
PESQUISA DE \\
NOVAS \\
EMPRESAS \\
QUE ATENDAM \\
NOSSAS \\
NECESSIDADES
\end{tabular} & $\begin{array}{l}\text { NA ÁREA DA } \\
\text { FÁBRICA }\end{array}$ & 0 MESMC \\
\hline & $\begin{array}{l}\text { - INSTALAR } \\
\text { ISCAS } \\
\text { LUMINOSAS DE } \\
\text { ULTRA VIOLETA }\end{array}$ & $\begin{array}{l}\text { PARA DIMINUIR A } \\
\text { QUANTIDADE DE } \\
\text { TRAÇAS DO } \\
\text { CACAU NA ÄREA } \\
\text { DA PRODUÇÄO }\end{array}$ & \begin{tabular}{|c} 
COMPRAS \\
(ROSEMERE) E \\
MANUTENÇÄO \\
(FAUSTINO)
\end{tabular} & | IMEDIATO & $\begin{array}{c}\text { REALIZAR A } \\
\text { COMPRA DAS } \\
\text { ISCAS E ISTALA } \\
\text { LAS NA } \\
\text { PRODUÇÄO }\end{array}$ & $\begin{array}{l}\text { NA ÁREA DA } \\
\text { PRODUÇÄOE } \\
\text { EMBALAGEM }\end{array}$ & $\begin{array}{l}\text { COMPRA } \\
\text { DE NO } \\
\text { MiNIIMOS } \\
\text { ISCAS }\end{array}$ \\
\hline
\end{tabular}

Figura 6: Plano de ação - 5W2H.

Fonte: A autora.

\subsubsection{Procedimentos Operacionais}

Os procedimentos são relatórios padrões escritos que descrevem de forma detalhada o passo a passo de como fazer determinado trabalho para assegurar que todos os produtos sairão igual à especificação padrão. Não são necessariamente ferramentas da qualidade, mas atuam em parceria com as mesmas [13]. A elaboração de procedimentos padrões não é apenas uma cobrança das legislações sanitárias, como a Resolução ANVISA/RDC No 275 de 22 de setembro de 2005 [14], mas especialmente um diferencial na solução dos problemas encontrados.

\subsection{Aplicação do TQC em Indústrias de Alimentos}

A contaminação alimentar é um dos principais fatores que favorecem os estudos e aplicação em busca da qualidade industrial e padronização em diversas indústrias de alimentos. Nos últimos anos, discussões sobre a qualidade dos alimentos têm sido mais frequentes em distintas áreas do conhecimento. Contudo, embora presente em diversas discussões e meios, a definição de qualidade dos alimentos não parece ser simples e tampouco apresenta consenso entre os que a discutem [15].

Gradativamente, a qualidade passou a ser associada a grandes estruturas e a aspectos sanitários, baseados na escala de produção e no modelo produtivo de grandes indústrias de alimentos. Para garantir e controlar essa 
qualidade adotaram-se sistemas e ferramentas de controle, padronização e rastreabilidade [16].

A Legislação Brasileira de Alimentos nasceu baseada na normatização do Food and Drugs Administration (FDA), dos Estados Unidos, e nas normas estabelecidas pela Comissão do Codex Alimentarius, e adota os padrões internacionais para a produção de alimentos. Nessa perspectiva, as exigências são estabelecidas em torno de um padrão de inocuidade, como as Boas Práticas de Fabricação (BPF) e a Análise de Perigos e Pontos Críticos de Controle (APPCC) ambas adotadas pelo FDA e referenciadas na Portaria ANVISA no 326 de 30 de julho de 1997 [15, 17].

Assim, a qualidade do sistema industrial de alimentos está fortemente associada à estrutura e às ferramentas de garantia de qualidade, ambas desenvolvidas e dimensionadas tendo em vista a realidade e a escala de produção de médias e grandes empresas, a partir dos riscos envolvidos na produção e transporte de alimentos em massa [2].

\subsection{A Indústria de Chocolate}

Chocolate é o produto obtido a partir da mistura de derivados de cacau (Theobroma cacao L.), massa (ou pasta ou líquor) de cacau, cacau em pó e ou manteiga de cacau, com outros ingredientes, contendo, no mínimo, $25 \%$ (g/100 g) de sólidos totais de cacau. $O$ produto pode apresentar recheio, cobertura, formato e consistência variados. Chocolate branco é o produto obtido a partir da mistura de manteiga de cacau com outros ingredientes, contendo, no mínimo, $20 \%(\mathrm{~g} / 100 \mathrm{~g})$ de sólidos totais de manteiga de cacau. O produto pode apresentar recheio, cobertura, formato e consistência variados [18]. A seguir, alguns tipos de chocolate:

- Coberturas de chocolate:

Para a confecção dos produtos de chocolate são utilizadas as coberturas de chocolate em estado sólido (necessitando de derretimento) ou líquido. Chocolate cobertura é o produto homogêneo preparado com massa ou pasta de cacau, manteiga de cacau e açúcares, com composição característica ao tipo de chocolate que se refere: amargo, ao leite ou branco. Existem no mercado coberturas que contêm, em sua formulação, gorduras sucedâneas da manteiga de cacau e que, por isso, não podem ser denominadas de chocolate cobertura [19].

- Produtos moldados:

Existem duas formas distintas para a confecção de produtos de chocolate: recobertos, quando o chocolate é derramado sobre um objeto doce (um núcleo) eliminando todo o excesso por agitação ou sopro; ou moldados, quando o chocolate é colocado em moldes para solidificar, podendo ser recheados ou não [20].

$\mathrm{Na}$ fabricação dos bombons moldados recheados ou, como é conhecido no mercado, as trufas, para a sua fabricação existe a necessidade de uma etapa prévia de formação da chamada casquinha de chocolate. Nesta etapa, os moldes são completamente preenchidos de chocolate, vibrados para retirada de bolhas de ar e invertidos para retirada do excesso de chocolate. Os equipamentos mais antigos exigiam que os recheios fossem depositados nas casquinhas, à temperaturas inferiores ao ponto de fusão do chocolate [21]. Após a preparação da casquinha, é possível adicionar o recheio de preferência e fechar o fundo com chocolate temperado, colocando para resfriar e obtendo o produto final.

\section{- Bombons:}

Bombom é o produto constituído por massa de chocolate ou por um núcleo formado de recheio, recoberto por uma camada de chocolate ou glacê. Pode conter outros ingredientes, desde que não descaracterizem o produto, e apresenta formato e consistência variados [22].

- Chocolate Diet.

O chocolate é conhecido por ser um produto rico em gordura e sacarose. Seu valor calórico pode ser alterado com uma diminuição na concentração de gordura. Entretanto, quando a concentração de gordura é menor que $27 \%$ de seu peso, o chocolate perde a sua suavidade e seu derretimento na boca [21].

A confeç̧ão do chocolate foi, durante cerca de um século, uma indústria tradicional administrada por artesãos que desenvolveram métodos individuais de trabalho e sabores particulares para os seus produtos. Com a demanda por custos mais baixos, a manufatura industrial foi cada vez mais mecanizada, somando-se a isso o progressivo avanço da ciência e da tecnologia usada para controle das plantas de produção e para a melhoria da eficiência industrial [23].

A composição precisa do chocolate varia em todo o mundo devido à diferença de gostos e legislações, 
que regulam as porcentagens de cacau e sólidos do leite adicionais, quantidade e tipos de gorduras vegetais permitidas. As gorduras encontradas no chocolate, por exemplo, incluem a manteiga de cacau, a gordura do leite e gordura vegetal [24].

De acordo com a Associação Brasileira da Indústria de Chocolates, Cacau, Amendoim, Balas e Derivados (ABICABI), o setor cresceu a uma média de $20 \%$ ao ano e, entre 2004 e 2011, a participação do segmento aumentou de $40 \%$ para $54 \%$. Destaque para o mercado de chocolates Premium que representava $1 \%$ do mercado brasileiro em 2012 e passou a atingir $6 \%$, ou 30 mil toneladas de 473 mil toneladas anuais [25].

Segundo a ABICABI [25] entre 2012 e 2013 o setor teve um pequeno decaimento de produção, uma variação de $0,3 \%$, correspondendo a $800 \mathrm{mil}$ toneladas de chocolate produzido. Mas, em comparação aos anos anteriores, manteve sua média de crescimento juntamente com o crescimento do seu consumo, como mostra o Gráfico 1.

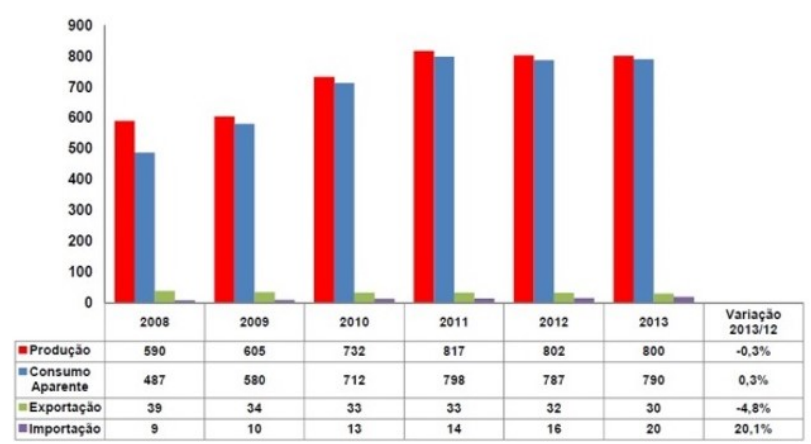

Gráfico 1: Percentual de crescimento do consumo de chocolate no Brasil de 2008-2013. [25]

\section{Metodologia}

Este trabalho acadêmico apresenta um projeto de intervenção em uma empresa localizada na Região Metropolitana do Recife, que produz e comercializa chocolates.

Quando identificado o problema de contaminação, por meio de reclamações de funcionários e clientes, foi proposta a aplicação do TQC, com o uso das ferramentas da qualidade, iniciando pela implantação de uma lista de verificação criada pela autora para acompanhar a possível contaminação interna, bem como uma lista de verificação para monitorar as reclamações das lojas.

Foram realizadas visitas mensais nas lojas da empresa, no período de Junho a Dezembro de 2016, bem como monitoramento do processo fabril, com a aplicação das listas de verificação supracitadas.

Para análise e solução dos problemas, foram utilizadas as ferramentas da qualidade como brainstorming diagrama de Ishikawa, diagrama de Pareto, histograma e 5W2H.

\section{Resultados}

\subsection{Implantação das Ferramentas da Qualidade}

No mês de Março de 2016, o setor de controle de qualidade da empresa estudada recebeu reclamações internas e externas, alguns casos acompanhados das amostras, sobre produtos que apresentaram problemas de contaminação (larvas ou mofo). A partir daí, foi sugerida a metodologia TQC, com o apoio das ferramentas da qualidade para identificar e solucionar os problemas dos produtos.

Com as primeiras informações que chegaram dos gerentes das lojas e dos vendedores foi elaborado o diagrama de Pareto, de forma a priorizar o problema mais grave e começar a atuar nele.

O diagrama de Pareto apresentado no Gráfico 2 apoia na percepção de que o problema da fábrica era a perda de produtos devido à contaminação. A empresa estudada possui duas linhas principais de produtos, a linha - ao leite e a linha - fracionada (cobertura), foi identificado que, para uma amostra de 100 produtos de cada linha, 80 da linha ao leite estavam contaminados para uma quantidade de 20 produtos da linha fracionada, deixando claro para empresa que deveria iniciar suas atividades e análise e melhoria pela linha ao leite.

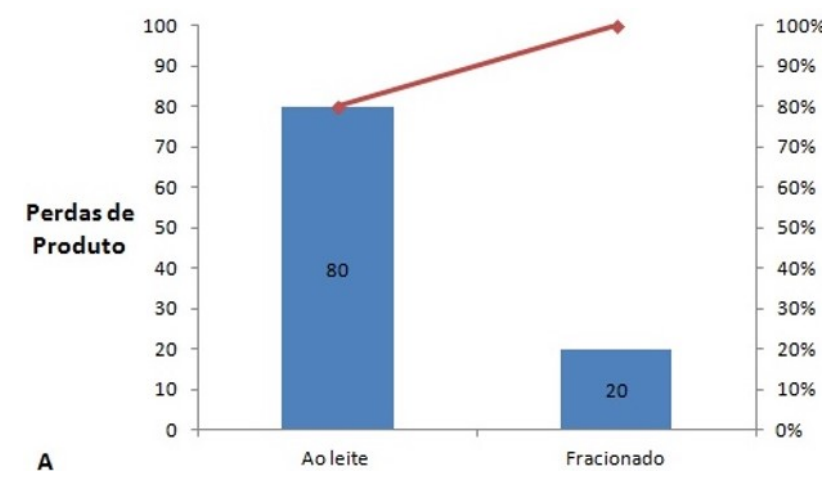

Gráfico 2: Diagrama de Pareto para as perdas de produtos contaminados.

Fonte: A autora.

http: / / dx.doi.org/10.25286/repa.v2i2.557 
Como o diagrama de Pareto apoia na priorização dos problemas com maior incidência, foi realizada uma nova estratificação do diagrama de Pareto. No Gráfico 3, é possível constatar que, dos 80 produtos analisados da linha ao leite, 60 itens eram trufas, 10 eram bombons e 10 eram produtos só de chocolate ao leite. Sendo assim, a empresa concluiu que o grande foco de contaminação estava nas trufas e que estas deveriam ter prioridade no estudo das causas dos problemas.

Uma vez identificado que a abordagem das trufas seria priorizada, foi realizado um brainstorming, para que os funcionários participassem com as suas ideias, sendo estes a equipe envolvida na produção das trufas e, também, as pessoas do setor de controle da qualidade. Com as sugestões, foi elaborado o diagrama de causa e efeito apresentado na Figura 7.

Identificou-se que os possíveis problemas das trufas contaminadas seriam provenientes: da mão de obra, que estaria realizando procedimentos inadequados, manipulando sem higiene ou realizando suas atividades sem atenção; do método, que estaria relacionado a má elaboração do procedimento; e do meio ambiente, com relação ao meio externo ou interno, como poluição, calor, poeira.

Quando avaliado o diagrama de causa e efeito, foram observadas várias causas do problema de contaminação nas trufas. Desta forma, foi elaborado um plano de ações corretivas para atuar nestas causas, conforme apresentado no Apêndice 1. A seguir, as causas e soluções descobertas com a aplicação das ferramentas da qualidade.

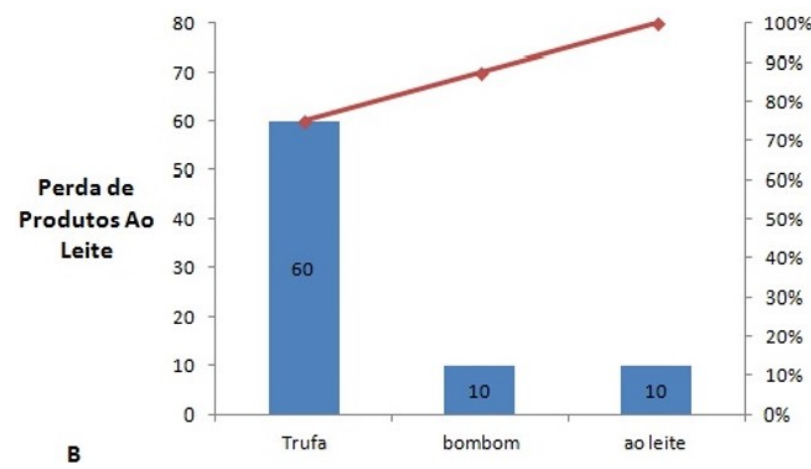

Gráfico 3: Diagrama de Pareto estratificado para as perdas de produtos ao leite contaminados.

Fonte: A autora.

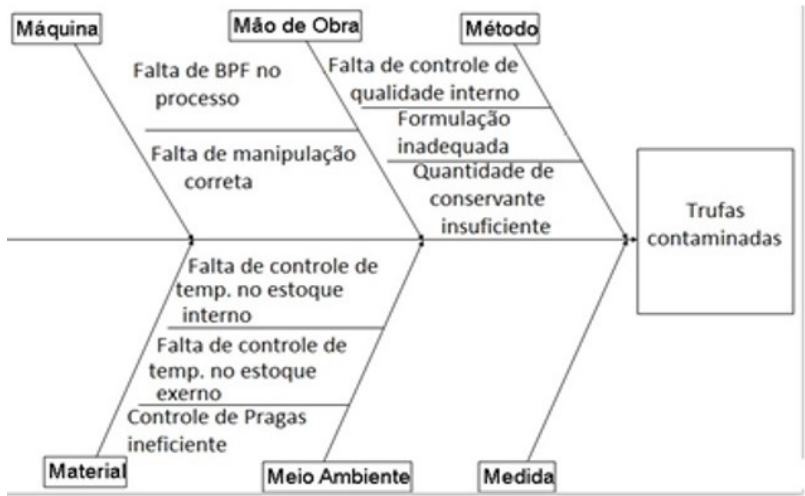

Figura 7: Diagrama de Pareto para as perdas de produtos contaminados.

Fonte: A autora.

\subsection{Causas e Soluções}

\subsubsection{Primeira Causa}

A empresa que presta serviço de controle de pragas não estava sendo eficiente, pois no setor de produção surgiam muitas traças do cacau (mosquito). Ações corretivas:

- Selecionar uma nova prestadora de serviço, que viesse a atuar especificamente neste problema;

- Instalar iscas luminosas ultra violeta no setor de produção e embalagem, que atraem mais rapidamente as traças de cacau, possibilitando a sua prisão e descarte.

A mudança da empresa de controle de pragas, juntamente com a instalação das iscas luminosas, foi realizada no final do mês de Abril de 2016 .

\subsubsection{Segunda Causa}

A quantidade de conservante utilizado nas trufas pode não ser a suficiente para sua conservação. Ações corretivas:

- Realização de teste piloto com o aumento do conservante no recheio das trufas, acompanhando o seu desempenho;

- Realização de análises mais profundas no percentual de cada componente utilizado para o recheio, quando se chegou à conclusão de que o percentual de água na formulação estava favorecendo o crescimento de microorganismos.

A resolução no 387, de 05 de agosto de 1999 [26] descreve a quantidade máxima de aditivos dentre eles 
os conservantes para trufas. Desta forma foram realizados testes pilotos com 0 aumento de conservante de acordo com a legislação no inicio de Abril de 2016. Logo após os testes a proposta foi descartada, pois foi percebido que este aumento causava alteração no sabor do recheio. Além disso, foram coletadas amostras dos recheios com a quantidade de conservante atual e amostras com o aumento do conservante. Ambas as amostras não apresentaram presença de mofo ou larvas. Como a quantidade de conservante utilizada anteriormente estava conforme os padrões, a empresa optou por mantê-la.

\subsubsection{Terceira Causa}

Formulação das trufas inadequada devido ao alto teor de umidade. Foi estudada a formulação das trufas e identificou-se um alto teor de umidade sendo necessária uma nova formulação, com teor de umidade mais baixo. Ação corretiva:

- Foi estudada uma nova formulação que atendesse as necessidades da produção, pois a adoção da formulação mais úmida proporcionava que o recheio deslizasse adequadamente na máquina de trufas. No entanto, foram realizados vários testes com diferentes proporções, até que se atingiu um padrão de formulação com menor teor de umidade, que foi colocado em prática na segunda quinzena de Maio de 2016.

\subsubsection{Quarta Causa}

A falta de controle interno dos produtos fabricados. Ação corretiva:

- Coletar amostras de todo produto acabado fabricado, registrando o dia de fabricação, lote e operador para elaborar uma planilha de rastreabilidade do processo de fabricação do chocolate. Dessa forma, seria mais fácil controlar o processo em todas as suas etapas e também alcançar 0 atendimento das legislações aplicáveis (RDC da ANVISA n 275/2002 e Portaria ANVISA n0326/1997) [14 e 17].

\subsubsection{Quinta Causa}

A falta de controle sensorial dos produtos acabados. Ações corretivas:

- Iniciou-se um processo de análise sensorial (sabor, odor e textura) interna de todo lote de trufas que era produzido.

- Foi elaborada uma ficha de análise sensorial das trufas, para que fosse possível passar a identificar a alteração de sabor, cor, textura e a presença ou ausência de mofo ou larva.

O controle de qualidade interno das trufas começou a ser realizado no mês de Abril de 2016. O controle sensorial das trufas foi realizado através de análises visuais de textura e presença ou ausência de mofo e da prova degustativa do sabor e odor das trufas. O Gráfico 4 apresenta o resultado de não conformidades apresentadas no controle de qualidade das trufas, tornando possível observar que, nos meses de Maio a Julho, algumas trufas apresentaram contaminação mesmo depois das modificações realizadas. No entanto, foi observado que muitas trufas já estavam no depósito antes da implantação das ações corretivas, acusando que sua fabricação não tenha sido impactada por algumas das alterações, já que o controle por meio de análises sensoriais começou a ser realizado em Abril de 2016 e as implantações mais significativas de controle das trufas foram realizadas em sensoriais foram registradas um mês antes das implantações (em Abril) para tornar possível verificar se realmente iria ocorrer a diminuição de contaminação de mofo nas trufas. Em Setembro, Outubro e Novembro de 2016, algumas trufas apresentaram contaminação por mofo e ações corretivas nos procedimentos de manipulação foram tomadas para evitar maiores índices posteriores.

O Gráfico 4 apresenta informações coletadas através das fichas de análise sensorial, entre os meses de Abril a Dezembro de 2016.

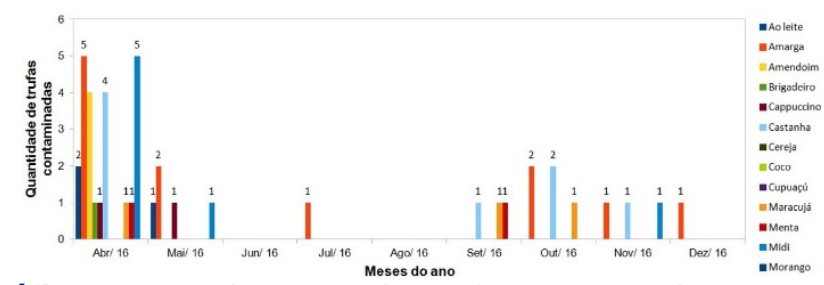

Gráfico 4: Controle interno das trufas contaminadas. Fonte: A autora.

\subsubsection{Sexta Causa}

http://dx.doi.org/10.25286/repa.v2i2.557 
O controle da temperatura do ambiente no qual o chocolate está estocado deve ser controlado para que não ocorram contaminações. Ações corretivas:

- Implantação do controle de temperatura e realização de visitas às lojas da empresa estudada, presentes na região Metropolitana do Recife, com o intuito de verificar o cumprimento de tal controle dos estoques externos, bem como a avaliação da forma de armazenamento dos produtos.

- Foi realizada também uma visita ao estoque da fábrica para verificar o cumprimento do controle da temperatura, pois este não fica exatamente nas dependências da fábrica, mas está localizado num galpão em outro local, já que os produtos da linha ao leite precisam estar num ambiente com temperatura máxima de $22^{\circ} \mathrm{C}$ para manterem as suas características.

Em ambos os locais, foi verificado que a temperatura e o armazenamento dos produtos estão de acordo com as normas de preservação de qualidade do chocolate.

\subsubsection{Sétima Causa}

Falta de acompanhamento de reclamações das lojas sobre os produtos. Ação corretiva:

- Elaboração de uma lista de verificação para registro e acompanhamento das reclamações nas lojas. De acordo com o Gráfico 5, é possível perceber que, antes da implantação da lista de verificação nas lojas e dos controles de qualidade, o índice de produtos contaminados era alto.

Após a implantação do controle de qualidade na fábrica, principalmente das trufas, as reclamações das lojas diminuíram consideravelmente quando comparado o mês de Março de 2016 com os meses a partir de Julho de 2016.

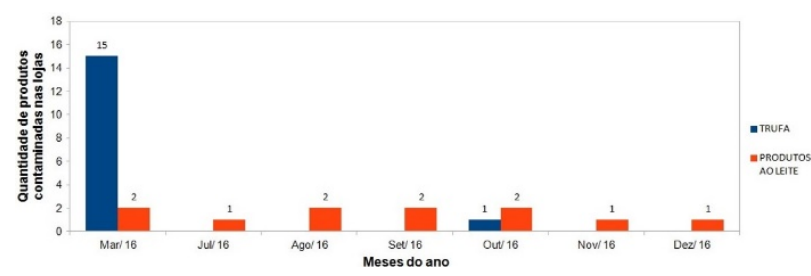

Gráfico 5: Controle externo dos produtos contaminados nas lojas antes e após as implantações de controle de qualidade. Fonte: A autora.

\subsubsection{Oitava Causa}

Falta de conscientização sobre as Boas Práticas de Fabricação, conjunto de regras definidas na legislação sanitária pela RDC no 326/1997 [18]. Ações corretivas:

- Para realizar a conscientização dos colaboradores e evitar a contaminação por agentes físicos ou biológicos, foi realizado um treinamento de Boas Práticas de Fabricação, voltado para a fabricação de alimentos.

- Foi implantada uma rotina de diálogo diário para que todos os colaboradores entendessem a necessidade do uso de luvas e máscaras na área de fabricação e da assepsia correta das mãos, com a finalidade de evitar possíveis contaminações.

No início de Outubro de 2016 foi realizado um treinamento para todos os integrantes da fábrica mostrando os conceitos, os benefícios e os problemas da não aplicação do BPF.

\subsubsection{Nona Causa}

Procedimentos e formulações desatualizados ou inexistentes. Ação corretiva:

- Atualização de alguns procedimentos padrões, como formulação do recheio das trufas e a criação de alguns procedimentos diários, como a análise periódica das trufas e lista de acompanhamento de reclamações nas lojas.

\subsection{Monitoramento e Melhoria Contínua}

O monitoramento das ações implantadas passou ser constante, em atendimento às premissas do ciclo PDCA. Por meio dele, observa-se que as principais ações realizadas para melhoria das trufas, tais como troca da prestadora de serviço do controle de pragas, instalação de iscas luminosas ou formulação alternativa de recheio com menos umidade, diminuíram a incidência de reclamações. Isto é perceptível nos Gráficos 4 e 5, que apresentam diminuição de contaminações na produção e no estoque externo (nas lojas).

A continuidade dos monitoramentos implantados e a garantia da qualidade das ações implantadas devem ser mantidos e acompanhados, em cumprimento à 
etapa C (Check) do ciclo PDCA, sendo esta uma das características da qualidade total, o que torna possível a melhoria contínua.

\section{Conclusões}

A demanda por chocolates e seus derivados cresce continuamente a cada ano, e junto com esse crescimento, as empresas desse ramo aumentam seus investimentos com o objetivo de alavancar suas capacidades de produção para acompanhar essa tendência.

O TQC juntamente com as ferramentas da qualidade tiveram grande importância na identificação e solução do problema de contaminação do chocolate, abordado no presente trabalho, pois o foco principal do controle da qualidade total é satisfação dos clientes na entrega de melhores produtos.

A empresa estudada resolveu colocar em prática as ferramentas da qualidade logo de imediato para resolver a situação identificada, antes que se tornasse mais grave, o que poderia comprometer a saúde dos consumidos ou a imagem da empresa.

O problema de contaminação de mofo das trufas de chocolate foi criteriosamente analisado e solucionado, como pode ser visualizado no Gráfico 5, permitindo à empresa seguir para a análise do segundo problema evidenciado no gráfico de Pareto: contaminação produtos fracionados (coberturas).

Diante do resultado obtido, ficou comprovado que a aplicação da metodologia adotada foi bem sucedida, torando possível não apenas a solução do problema, mas uma série de ganhos intrínsecos relacionados a ela, tais como conhecer melhor o seu processo e instalações, capacitar e engajar a sua equipe, usando de forma sistemática as regras e ferramentas escolhidas. Devido aos resultados obtidos, a empresa irá seguir o princípio de melhoria contínua e aplicar os mesmos processos para outras linhas da fábrica.

\section{Referências}

[1] FILHO, M.C. As ferramentas de qualidade no processo produtivo com enfoque no processo enxuto. 2011. Monografia (curso de MBA em Gestão da manutenção, produção e negócios) Faculdade Pitágoras, Minas Gerais. 2011.

[2] MALUF, R.S.J. Segurança Alimentar e Nutricional. Petrópolis: Vozes, p. 174, 2007.
[3] FERREIRA, R.R. O Kaizen como sistema de melhoria contínua dos processos: um estudo de caso na Mercedes Benz do Brasil LTDA planta juiz de fora. 2009. Monografia (curso de Secretariado Executivo Trilíngüe) - Universidade Federal de Viçosa, Minas Gerais. 2009.

[4] PAZZINATO, A.L.; SENISE, M.H. História Moderna e Contemporânea. São Paulo: Ed Ática, 2004.

[5] GARVIN, D.A. Gerenciando a qualidade: a visão estratégica e competitiva. $1^{\text {aed. Rio de }}$ Janeiro: Qualitymark, p. 357,1992.

[6] SENE, E.; MOREIRA, J.C. Geografia: Espaço geográfico e globalização. São Paulo: Scipione, 2002.

[7] CARVALHO, B. Gestão da Qualidade I: Material de apoio - Evolução Histórica da Qualidade. Disponível em: < file:///C:/Users/Priscilla\%20Correa/Downloads/E VOLU\%C3\%87\%C3\%830+HIST\%C3\%93RIC A+DA+QUALIDADE.pdf >. Acesso em: 10 de Agosto de 2016.

[8] FALCONI, V. TQC Controle da Qualidade Total no estilo japonês. Nova Lima: Editora Falconi - 9 a Ed., p. 286, 2014.

[9] SILVA, R.K.V.; BARBOSA, A.F.B. Gestão da Qualidade - Os principais marcos e como influenciaram as empresas. Revista de Engenharia e Pesquisa Aplicada, vol. 1, no 1, 2016.

[10] MARIANI, C.A. Método PDCA e ferramentas da qualidade no gerenciamento de processos industriais: um estudo de caso. Revista de Administração e Inovação, vol. 2, no 2, p. 110126, 2005.

[11] MENEZES, F.M. MASP - Metodologia de Análise e Solução de Problemas. Produttare. Agência Brasileira de Desenvolvimento Industrial - ABDI. Porto Alegre. 2013

[12] SEBRAE. Manual de Ferramentas da Qualidade. 2005. Disponível em: < http://www.dequi.eel.usp.br/ barcza/Ferrament asDaQualidadeSEBRAE.pdf > Acesso em Agosto de 2016.

[13] VERGANI, A. Procedimento Operacional Padrão - POP. Orientações para elaboração. Disponível em: < http://docplayer.com.br/3278664-Procedimento-

http: / / dx.doi.org/10.25286/repa.v2i2.557 
operacional-padrao-pop-orientacoes-paraelaboracao-enfa-assione-vergani-visa.html >. Acesso em Setembro de 2016.

[14] BRASIL. Ministério da Saúde. Agência Nacional de Vigilância Sanitária. Legislação. VisaLegis. Resolução RDC n. 275, de 21 de outubro de 2002. Aprova Regulamento Técnico de Procedimentos Operacionais Padronizados aplicados as Estabelecimentos Produtores/Industrializadores de Alimentos e a Lista de Verificação das Boas Práticas de Fabricação em Estabelecimentos Produtores/Industrializadores de Alimentos. Disponível em:

http://www.rio.rj.gov.br/dlstatic/10112/5125403 /4132350/ResoluuoRDC27521.10.2002.pdf > Acesso em: Novembro de 2016.

[15] CRUZ, F.T.; SCHNEIDER, S. Qualidade dos alimentos, escalas de produção e valorização de produtos tradicionais. Revista Brasileira de Agroecologia, V. 5, p. 22-38, 2010.

[16] GIORDANO, J.C.; GALHARDI, M.G. Análise de perigos e pontos críticos de controle. Campinas: SBCTA, p. 92, 2004.

[17] BRASIL. Ministério da Saúde. Agência Nacional de Vigilância Sanitária. Legislação. VisaLegis. Resolução RDC n. 326, de 30 de julho de 1997. Aprova Regulamento Técnico para Condições Higiênico-sanitárias e de Boas Práticas de Fabricação para Estabelecimentos Produtores/Industrializadores de Alimentos. Disponível em: <http://portal.anvisa.gov.br/documents/33916/3 88704/Portaria\%2BSVSMS\%2BN. \%2B326\%2Bde \%2B30\%2Bde\%2BJulho\%2Bde\%2B1997.pdf/87 a1ab03-0650-4e67-9f31-59d8be3de167 Acesso em: Novembro de 2016.

[18] BRASIL. Ministério da Saúde. Agência Nacional de Vigilância Sanitária. Legislação. VisaLegis. Resolução RDC n. 264, de 22 de setembro de 2005. Aprova Regulamento Técnico para Fixação de Identidade e Qualidade de Chocolate e Chocolate Branco. Disponível em: <http://portal.anvisa.gov.br/documents/33916/3 94219/RDC_264_2005.pdf/7a0256b4-79e14a5a-8129-7f37ba6f2cd7> Acesso em: 31 julho. 2016.

[19] LANNES, S.C.S. Estudo das propriedades físico-químicas e de textura de chocolates. 1997. 175p. Tese (Doutorado) - Faculdade de Ciências
Farmacêuticas, Universidade de São Paulo, São Paulo. 1997

[20] BECKETT, S.T., (Ed.). Fabricación y utilización industrial del chocolate. Zaragoza: Acribia, p.276-277,1994.

[21] RICHTER, M.; LANNES, S.C.S. Ingredientes usados na indústria de chocolates. Revista Brasileira de Ciências Farmacêuticas, vol. 43, n³, 2007.

[22] BRASIL. Ministério da Saúde. Agência Nacional de Vigilância Sanitária. Legislação. VisaLegis. Resolução RDC n. 265, de 22 de setembro de 2005. Aprova Regulamento Técnico para balas, bombons e gomas de mascar. Disponível em: <http://elegis.anvisa.gov.br/leisref/public/showA ct.php?id=18824> . Acesso em: 31 de julho 2016.

[23] BONZAS, J.; BROWN, B.D. Interactions affecting microstructure, texture, and rheology of chocolate confectionery products. In: GAONKAR, A.G., (Ed.). Ingredient interactions: effects on food quality. New York: Marcel Dekker, 1999. p.451-523. (Food Science and Technology, 66).

[24] MARTIN, A.V. Chocolate confectionery. In: MAN, C. M. D.; JONES, A. A., (Eds.). Shelf life evaluation of foods. London, New York: Blackie Academic, p. 216-234, 1994

[25] ABICABI - Associação Brasileira da Indústria de Chocolates, Cacau, Amendoim, Balas e Derivados. Disponível em: < http://www.abicab.org.br/ > Acesso em: 31 de julho de 2016.

[26] BRASIL. Ministério da Saúde. Agência Nacional de Vigilância Sanitária. Legislação. VisaLegis. Resolução RDC n. 387, de 05 de agosto de 1999. Aprova Regulamento Técnico do uso de aditivos alimentares, estabelecendo suas funções e seus limites máximos para a categoria de alimentos 5: balas, confeitos, bombons, chocolates e similares. Disponível em: < http://portal.anvisa.gov.br/documents/33916/38 8729/Microsoft\%2BWord\%2B-

$\% 2$ BResolu $\% 25$ C3\%25A7\%25C3\%25A3o\%2Bn $\% 25$ C2\%25BA\%2B387\%2Bde\%2B05\%2Bde\%2B agosto\%2Bde\%2B1999.pdf/1240800a-0d4b$4 c c 9-8 d 9 c-5211$ e9c3fb93 >. Acesso em Outubro de 2016. 
Revista de Engenharia e Pesquisa Aplicada (2017) Vol.2 No.2. 


\section{Apêndice I}

\begin{tabular}{|c|c|c|c|c|c|c|c|c|c|c|}
\hline 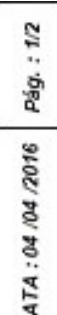 & 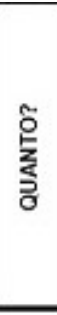 & 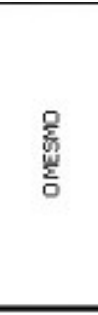 & 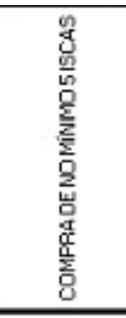 & 品 & 号 & 总 & 号 & $\underset{\mathrm{H}}{\stackrel{P}{\mathrm{H}}}$ & 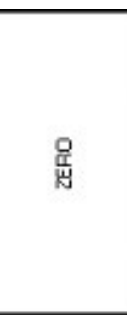 & 总 \\
\hline 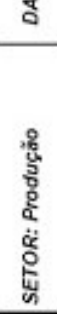 & 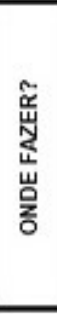 & 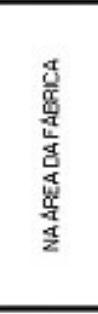 & 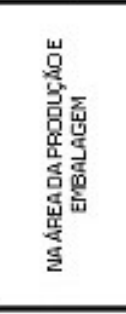 & 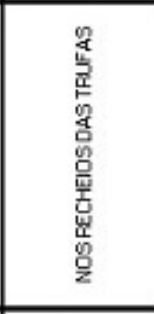 & 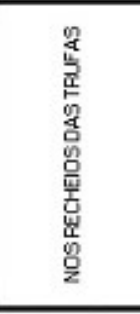 & 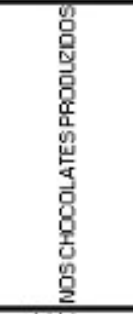 & 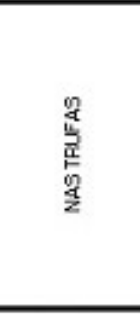 & 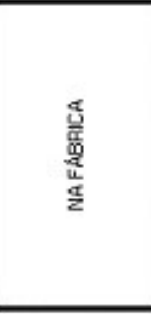 & 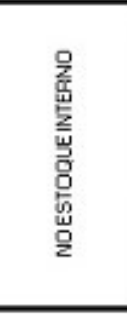 & 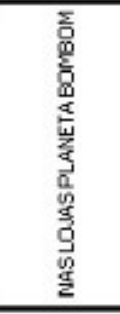 \\
\hline $\begin{array}{l}\text { y } \\
\vdots \\
\vdots \\
\vdots\end{array}$ & 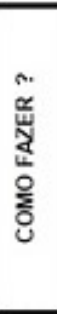 & 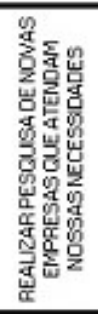 & 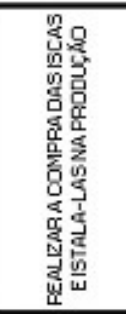 & 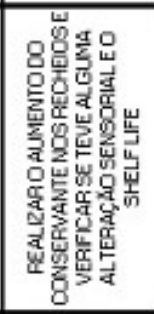 & 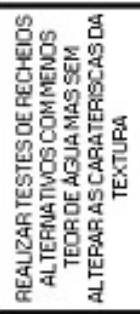 & 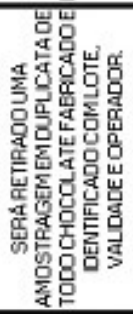 & 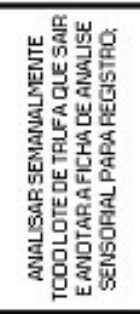 & 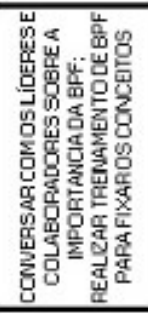 & 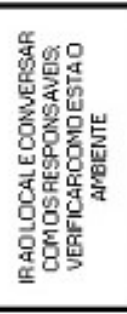 & 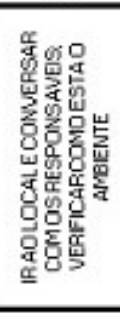 \\
\hline 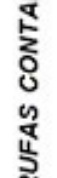 & $\begin{array}{l}\hat{8} \\
\vdots \\
\vdots \\
0\end{array}$ & $\begin{array}{l}\text { 景 } \\
\text { 总 }\end{array}$ & $\begin{array}{l}\frac{g}{2} \\
\frac{\mathrm{g}}{\underline{z}}\end{array}$ & 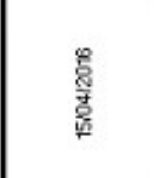 & $\begin{array}{l}\text { 总 } \\
\text { 产 }\end{array}$ & 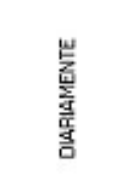 & $\begin{array}{l}\text { 訔 } \\
\text { 产 } \\
\text { 言 } \\
\text { 言 }\end{array}$ & 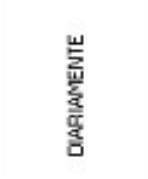 & 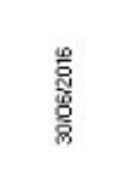 & 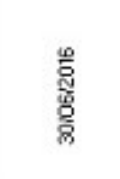 \\
\hline 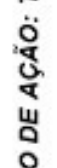 & 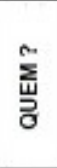 & 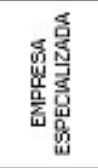 & 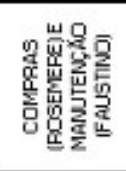 & 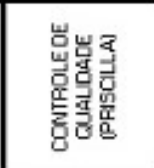 & 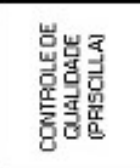 & 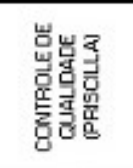 & 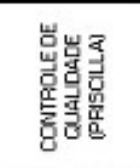 & 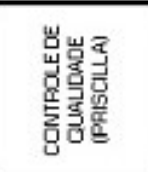 & 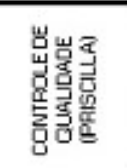 & 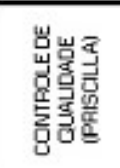 \\
\hline ख্ & 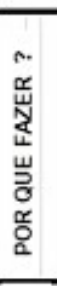 & 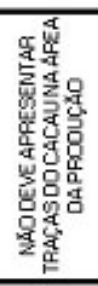 & 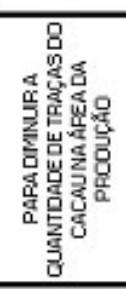 & 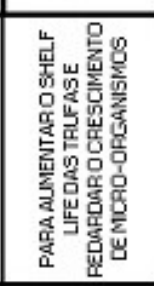 & 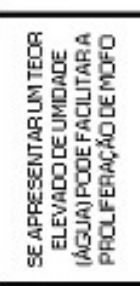 & 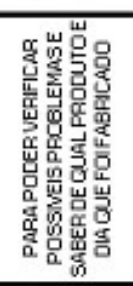 & 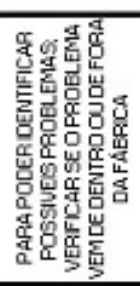 & 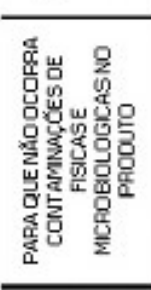 & 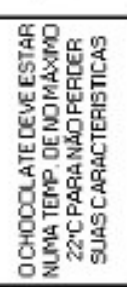 & 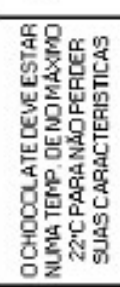 \\
\hline 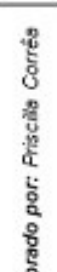 & 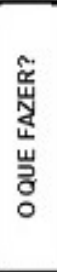 & 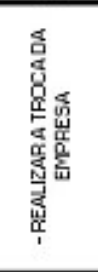 & 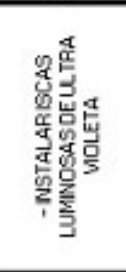 & 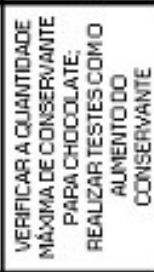 & 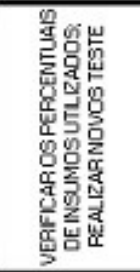 & 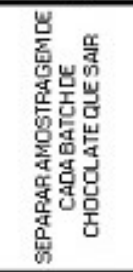 & 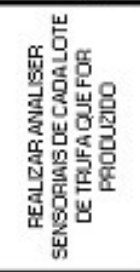 & 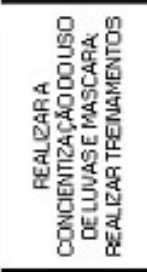 & 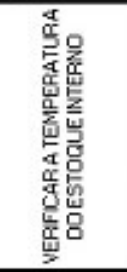 & 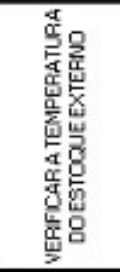 \\
\hline 负 & 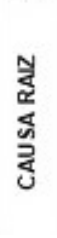 & \multicolumn{2}{|c|}{ 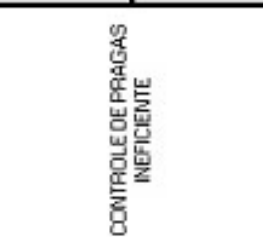 } & 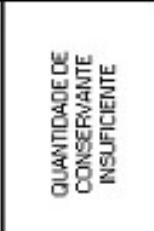 & 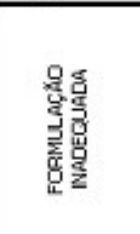 & \multicolumn{2}{|c|}{ 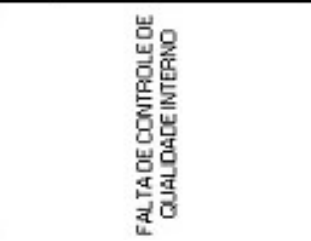 } & 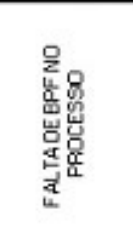 & 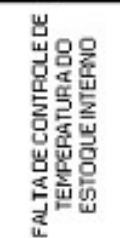 & 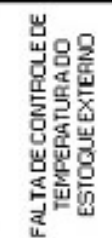 \\
\hline
\end{tabular}

